\title{
Flora do Rio de Janeiro: Haloragaceae
}

\author{
Flora of Rio de Janeiro: Haloragaceae
}

Isabelle Gomes Cardoso Machado da Costa $^{1}$, Andréia Donza Rezende Moreira ${ }^{1}$ \& Claudia Petean Bove $e^{1,2}$

\begin{abstract}
Resumo
O presente estudo tem como objetivo contribuir para o conhecimento das espécies de Haloragaceae ocorrentes no estado do Rio de Janeiro. O trabalho tem por base a análise morfológica de materiais depositados em herbários e coletas de campo, além da compilação de dados de literatura. Foram registrados dois gêneros e duas espécies: Laurembergia tetrandra e Myriophyllum aquaticum. Chave para identificação, descrições, ilustrações, dados sobre hábitat, fenologia e distribuição geográfica das espécies são apresentados.
\end{abstract}

Palavras-chave: Haloragaceae, florística, Rio de Janeiro, taxonomia.

\begin{abstract}
This study focuses on the Haloragaceae found in the state of Rio de Janeiro. It is based on a morphological analysis of herbaria collections, as well as on a review of the relevant literature and on collections in the field. A total of two genera and two species were recorded for the state: Laurembergia tetrandra e Myriophyllum aquaticum. An identification key, descriptions, illustrations, habitat data, phenology, and species distribution are also provided. Key words: Haloragaceae, floristic inventories, Rio de Janeiro, taxonomy.
\end{abstract}

Haloragaceae R. Br.

Ervas, subarbustos ou arbustos, monoicas, dioicas ou polígamas, aquáticas, palustres ou raramente terrestres. Folhas alternas, opostas, subverticiladas ou verticiladas, simples, inteiras ou multipartidas; estípulas presentes ou não; pecíolo presente, reduzido ou ausente; lâminas ovadas, espatuladas, lanceoladas ou lineares, glabras ou pilosas. Inflorescência em panícula, espiga, umbela, dicásio ou cimeira, por vezes em verticilos ou flores solitárias nas axilas. Flores unissexuais ou bissexuais, mono ou diclamídeas, actinomorfas; cálice 2-8-mero, valvar, gamossépalo, persistente ou caduco; corola 2-8-mera, imbricada, dialipétala; estames 2-8, homodínamos, filetes filiformes e muito curtos, anteras compridas, rimosas e basifixas; ovário ínfero, 1-4-carpelar, 1-4-locular, placentação pêndula, estiletes curtos ou nulos, estigmas 4-8. Fruto seco, indeiscente, nucáceo, núcula, esquizocarpo ou drupa, glabro ou piloso; sementes $1-4$, pêndulas.

A família possui oito gêneros e cerca de 150 espécies de distribuição subcosmopolita, sendo o centro de diversidade na Austrália (Kubitzki 2007; Souza \& Lorenzi 2005). Souza \& Lorenzi (2012) reconheceram três gêneros, Laurembergia Bergius, Myriophyllum L. e Proserpinaca L. e seis espécies como ocorrentes no Brasil. No Rio de Janeiro ocorrem os dois primeiros gêneros com uma espécie cada, em ambientes bem distintos conforme a espécie.

\section{Chave para identificação das espécies}

1. Ervas $15-45 \mathrm{~cm}$ compr.; caule avermelhado; folhas alternas ou opostas, simples, inteiras ou $2-5$ lobadas, heterofilia ausente; inflorescência em umbela axilar ou verticilar; estigmas mamiliformes

1. Laurembergia tetrandra

1'. Ervas 30-130 cm compr.; caule verde; folhas verticiladas, compostas, pectinadas; heterofilia presente; flores solitárias; estigmas fimbriados 2. Myriophyllum aquaticum

\footnotetext{
${ }^{1}$ Universidade Federal do Rio de Janeiro, Depto. Botânica, Museu Nacional, São Cristóvão, 20940-040, Rio de Janeiro, RJ, Brasil.

${ }^{2}$ Autor para correspondência: cpbove@hotmail.com
} 


\section{Laurembergia P. J. Bergius}

Ervas perenes, anfíbias ou emergentes; caule ereto, decumbente, radicante, prostrado, geralmente ramificado, glabro ou piloso. Folhas alternas, opostas ou ocasionalmente subverticiladas, simples; estípulas ausentes; pecíolo reduzido; lâminas espatuladas, lanceoladas ou lineares, margem inteira a denteada. Inflorescência em dicásio ou umbela, axilar e/ou verticilar. Flores estaminadas e bissexuais, curto-pediceladas, pistiladas subsésseis ou sésseis; cálice 4-8-mero, persistente, tubo costado, elipsoideo, subgloboso ou urceolado, glabro ou piloso; corola 4-mera, cuculada, glabra ou parcialmente pilosa; estames 4-8, anteras lineares ou oblongas; ovário 4-carpelar, 1-locular, 4-ovulado, estigmas 4-8, plumosos ou mamiliformes. Fruto nucáceo; semente 1.

Gênero com cerca de 4 espécies de distribuição pantropical e de áreas brejosas (Aona \& Amaral 2003; Heywood 2007). Está representado por apenas uma espécie no Brasil (Amaral \& Pellegrine 2015).

1.1. Laurembergia tetrandra (Schott) Kanitz in Mart., Fl. Bras. 13(2): 378.1882.

Fig. 1a,b,c,d

Ervas 15-45 cm alt.; caule avermelhado, radicante ou decumbente, glabro. Folhas alternas ou opostas, simples, inteiras a 2-5 lobadas; lâmina 3-25 × 0,3-7 mm, verde a avermelhada, espatulada ou linear-lanceolada, ápice agudo a obtuso, margem inteira ou serrilhada, base atenuada, glabra a ligeiramente pilosa. Inflorescência axilar disposta em verticilos ou umbelas, raramente flores solitárias. Flores pistiladas ou bissexuais; cálice 4-mero, 0,3-1,1 mm compr., avermelhado ou rosado, tubo subgloboso, lobo triangular, glabro; ovário globoso, estiletes curtos, estigmas 4, mamiliformes; pistiladas subsésseis, lobos do cálice reduzidos; bissexuais curto-pediceladas, pedicelo 0,4-0,6 mm compr.; corola 0,4-1,4 $\times$ $0,2-0,6 \mathrm{~mm}$, glabra ou pilosa no ápice; estames 4 , filetes $0,1-0,3 \mathrm{~mm}$ compr., anteras $0,3-1 \mathrm{~mm}$ compr., oblongas. Fruto subgloboso $0,3-1,1 \mathrm{~mm}$ compr., glabro.

Material selecionado: Araruama, Praia do Sossego, 10.II.2000, fl. e fr., B.M.B. Leite et al. 12 (R); Cabo Frio, Arraial do Cabo, ao nível do mar, 15.IV.1952, fr., L.B. Smith 6551 (R); Carapebus, Parque Nacional da Restinga de Jurubatiba, Lagoa Cabiúnas, 21.X.2003, fl. e fr., C.P. Bove et al. 1252 (R); Casimiro de Abreu, Praia da Barra de São João, 27-29.VII.1965, fl. e fr., $S$. Vianna 4367 (R); Macaé, Restinga de Cabiúnas, Canal Macaé-Campos, na margem do canal, 5.V.1981, fl. e fr.,
D. Araújo 4411 \& N.C. Maciel (GUA); Maricá, Área de proteção ambiental, no brejo ao leste do Morro do Monólo, 19.XI.1990, fl. e fr., D. Araújo 9197 (GUA); Quissamã, Parque Nacional da Restinga de Jurubatiba, a $19 \mathrm{~km}$ do centro de Quissamã, cerca de $1 \mathrm{~km}$ da praia do Pires, 20.XI.2001, fl. e fr., J. Fontella et al. 3576 (R); Rio das Ostras, Costa Azul, lado esquerdo da estrada, 11.II.2000, fl. e fr., B.M.B. leite et al. 18 (R); Rio de Janeiro, Recreio dos Bandeirantes, Pedra de Itaúna, 20.I.1965, fl. e fr., N. Santos 5378 (R); São João da Barra, Restinga alagadiça, 23.I.1976, fl. e fr., A.L. Peixoto \& O.L. Peixoto 819 (RB).

A espécie ocorre desde Pernambuco até o Rio Grande do Sul, em solos hidromórficos arenosos ou não; na restinga, cerrado e campo rupestre (Aona \& Amaral 2003). No Rio de Janeiro sua ocorrência é restrita à restinga, sendo encontrada em $\mathrm{M} 30, \mathrm{M} 32$, O29, P25, Q28, S24, T16, T20 e T27. Floresce e frutifica o ano inteiro.

Flores estaminadas são descritas por Kanitz (1882), Fevereiro (1972) e Aona (2005), no entanto estas não foram encontradas no material aqui analisado, proveniente do estado do Rio de Janeiro ou de outras localidades (SC e SP). A corola das flores bissexuais é descrita na literatura (Fevereiro 1972; Aona 2005) como nula ou rudimentar, porém o material proveniente do estado aqui analisado apresenta corola conspícua (Fig. 1e).

\section{Myriophyllum L.}

Ervas ou subarbustos, perenes ou raramente anuais, aquáticas ou paludosas; caule frequentemente rizomatoso, aerenquimatoso, ascendente ou flutuante, glabro. Folhas verticiladas, raramente alternas ou opostas, pectinadas, pinas filiformes ou lineares, geralmente heteromorfas, estípulas rudimentares presentes ou não, pecíolo presente ou reduzido. Inflorescência terminal arranjada em espiga, disposta em verticilos ou frequentemente solitárias nas axilas. Flores uni ou bissexuais, sésseis, subsésseis ou curto-pediceladas; cálice 2-4, glabro, tubo tetragonal ou obcônico, caduco; corola $2-4$, glabra, carenada, cuculada ou oblonga, ausente em flores pistiladas; estames 4-8, anteras lineares ou sub-arredondadas; ovário (2-)4-carpelar, 1-4-locular, estiletes geralmente ausentes, estigmas 4, plumosos ou fimbriados. Fruto nucáceo, coriáceo ou subcarnoso; semente oblonga, 1 por mericarpo.

O gênero compreende cerca de 40 espécies de distribuição cosmopolita (Orchard 1979). No Brasil está representada por três espécies (BFG 2015). Várias espécies foram introduzidas na aquariofilia, inclusive a ocorrente no Brasil. 

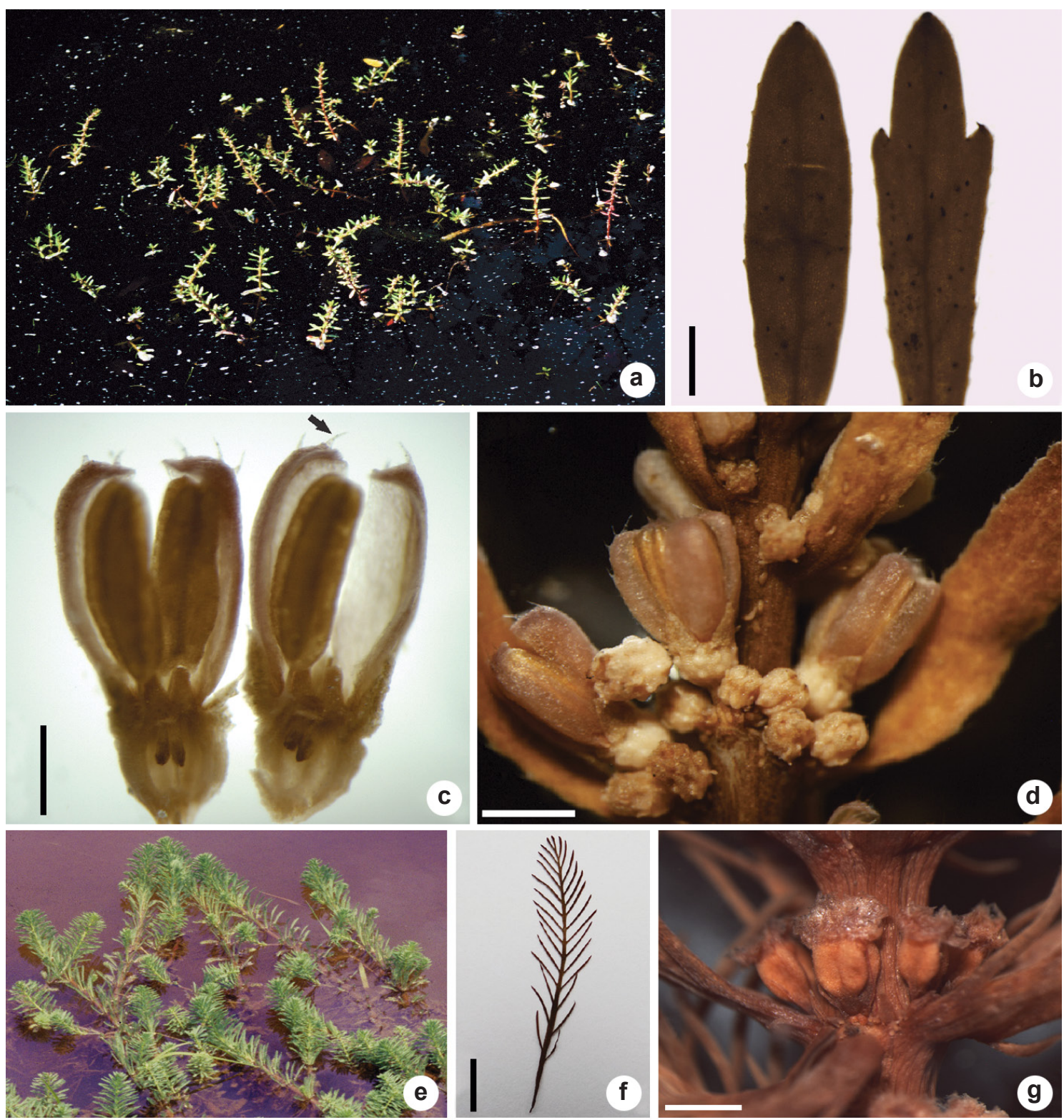

Figura 1 - a-d. Laurembergia tetrandra - a. hábito; b. folhas de lâmina inteira e 3-lobada (M. Coelho et al. 3); c. corte longitudinal da flor bissexual, seta evidenciando pétalas com tricomas; d. inflorescência com flores pistiladas (menores) e bissexuais (maiores) (I.M. Silva et al. 276). e-g. Myriophyllum aquaticum - e. hábito; f. folha composta pectinada (C.P. Bove et al. 1174); g. flores pistiladas nas axilas (V.L.G. Klein et al. 390). Escalas: $\mathrm{a}, \mathrm{e}=3 \mathrm{~cm} ; \mathrm{b}, \mathrm{g}, \mathrm{d}=1 \mathrm{~mm} ; \mathrm{f}=1 \mathrm{~cm} ; \mathrm{c}=0,5 \mathrm{~mm}$.

Figure 1 - a-d. Laurembergia tetrandra - a. habit; b. entire and 3-lobed leaves (M. Coelho et al. 3); c. longitudinal section of bissexual flower, arrow showing tricomes on the petals; $\mathrm{d}$. inflorescence with female (smaller) and bixessual (larger) flowers (I.M. Silva et al. 276). e-g. Myriophyllum aquaticum - e. habit; f. pectinate leaf (C.P. Bove et al. 1174); g. female flowers in axilar position (V.L.G. Klein et al. 390). Scales: $\mathrm{a}, \mathrm{e}=3 \mathrm{~cm} ; \mathrm{b}, \mathrm{g}, \mathrm{d}=1 \mathrm{~mm} ; \mathrm{f}=1 \mathrm{~cm} ; \mathrm{c}=0.5 \mathrm{~mm}$. 
2.1. Myriophyllum aquaticum (Vell.) Verdc., Kew Bull.28(1): 36. $1973 . \quad$ Fig. 1e,f,g Enydria aquatica Vell., Fl. Flumin. 1: 57, t. 150. 1829.

Myriophyllum brasiliense Cambess. in A.St;-Hil., Fl. Bras. Merid. 2:252.1830.

Ervas 30-130 cm compr., perenes, aquáticas. Folhas em verticilos de 4-6, pectinadas, pinas lineares, alternas, subopostas ou opostas, lâminas 9-52 mm compr., estípulas ausentes, pecíolo 1,5-5 $\mathrm{mm}$ compr. Flores unissexuais solitárias nas axilas, curto-pediceladas, pedicelo $0,2-0.5 \mathrm{~mm}$ compr.; bractéolas 2, 0,4-0,7 mm compr., filiformes ou pinatífidas; flores pistiladas cálice $4,0,5-0,8$ mm compr., esverdeado, tubo obcônico; ovário 4-locular, 4-carpelar, piriforme, estigmas brancos, sésseis e fimbriados.

Material selecionado: Barra do Piraí, 13.X.1986, fl., V.L.G. Klein et al. 390 (R); Campos dos Goytacazes, Lagoa Feia, M. Zippin 30386 (GUA); Itaboraí, a beira do Rio Guaraí, 29.X.1976, D. Araujo 1314 (GUA); Macaé, Lagoa Feia, Canto do Pastor, 10.VI.1980, D. Araujo \& N.C. Maciel 3806 (GUA); Paraty, Paraty-Mirim, no brejo, 12.II.1869, Glaziou 3662 (R); Petrópolis, Caelitu, XII.1943, fl.; O.C. Goes 863 (RB, epitipo); Piraí, Perto de Santana da Barra, lado direito da estrada em direção a barra do Piraí, 13.X.1986, fl., J.P.P. Carauta 5372 (GUA); Quissamã, Ponta Grossa dos Fidalgos, Lagoa Feia, 11.XII.2004, C.P. Bove et al. 1417 (R); Rio de Janeiro, margem do rio São João, 3.II.1970, S.P. Santos 146718 (RB); Resende, Porto Real, Rio Paraíba do Sul, 22.X.1981, J.P.P. Carauta et al. 3889 (R); Cantagalo, Santa Rita da Floresta, próximo a cachoeira São Lourenço, 25.VI.2004, C.P. Bove \& R. Occhi 1345 (R); Silva Jardim, Rio, São João, 12.V.1976, D. Araujo et al. 1088 (GUA); Teresópolis, 31.VII.1958, fl., A. Ab $52(\mathrm{HB})$.

Material adicional examinado: Santa Catarina, s/d, fl., F. Muller 182681(RB).

A espécie é nativa da América do Sul (Orchard 1979), no Brasil ocorre na Bahia, São Paulo, Paraná, Santa Catarina e Rio Grande do Sul
(Amaral \& Pellegrine 2015). No Rio de Janeiro em I32, K24, M32, O29, P5, P11, P17, P18, R10, R20, R24, T16, X2, floresce nos meses de julho, outubro e dezembro. Frutos desta espécie não foram encontrados no material aqui analisado.

A maioria do material proveniente do Rio de Janeiro contém indivíduos estéreis. Apenas quatro exsicatas encontram-se férteis (dentre elas o epitipo), entretanto apresentam somente flores pistiladas; apenas o material coletado em Santa Catarina possui flores pistiladas e estaminadas.

\section{Agradecimentos}

Aos curadores e equipe dos herbários GUA, HB, R e RB. Ao Conselho Nacional de Desenvolvimento Científico e Tecnológico (Edital PROTAX, Processo 562251/2010-3, a bolsa de Produtividade de C.P.B., e a bolsa de Iniciação Científica CNPq/PIBIC de I.G.C.M.C.).

\section{Referências}

BFG. 2015. Growing knowledge: an overview of seed plant diversity in Brazil. Rodriguésia 66: 1085-1113.

Heywood, V.H.; Brummitt, R.K.; Culham, A. \& Seberg, O. 2008. Flowering plant families of the World. Royal Botanic Gardens, Kew. 159p.

Kanitz, A. 1882. Haloragaceae. In: Martius, C.F.P. \& Eichler, A.G. (eds.). Flora brasiliensis. Typographia Regia. Munchen, Wien. Vol. 13, pars 2, pp. 373-388.

Kubitzki, K. 2007. Haloragaceae. In: Kubitzki, K. (ed.). The families and genera of vascular plants. Vol. 9. Springer-Verlag, Berlin. Pp. 184-190.

Orchard, A.E. 1979. Myriophyllum (Haloragaceae) in Australasia. I. New Zealand: a revision of the genus and a synopsis of the family. Brunonia 2: 247-287.

Souza, V.C. \& Lorenzi, H. 2012. Botânica sistemática: guia ilustrado para identificação das famílias de Fanerógamas nativas e exóticas no Brasil, baseado em APGIII. Nova Odessa, São Paulo. 263p.

\section{Lista de exsicatas}

Ab, A. 52 (2.1); Araújo, D. 1088 (2.1), 1314 (2.1), 3806 (2.1), 4411 (1.1), 9197 (1.1); Bove, C.P. 1252 (1.1), 1345 (2.1), 1417 (2.1); Carauta, J.P.P. 3889 (2.1), 5372 (2.1); Fontella, J. 3576 (1.1); Glaziou, A. 3662 (2.1); Goes, O.C. 863 (2.1); Klein, V.L.G. 390 (2.1); Leite, B.M.B. 12 (1.1), 18 (1.1); Muller, F. 182681 (2.1); Peixoto, A.L. (1.1); Santos, N. 5378 (1.1); Santos, S.P. 146718 (2.1); Smith, L.B. 6551 (1.1); Vianna, S. 4367 (1.1); Zippin, M. 30386 (2.1). 